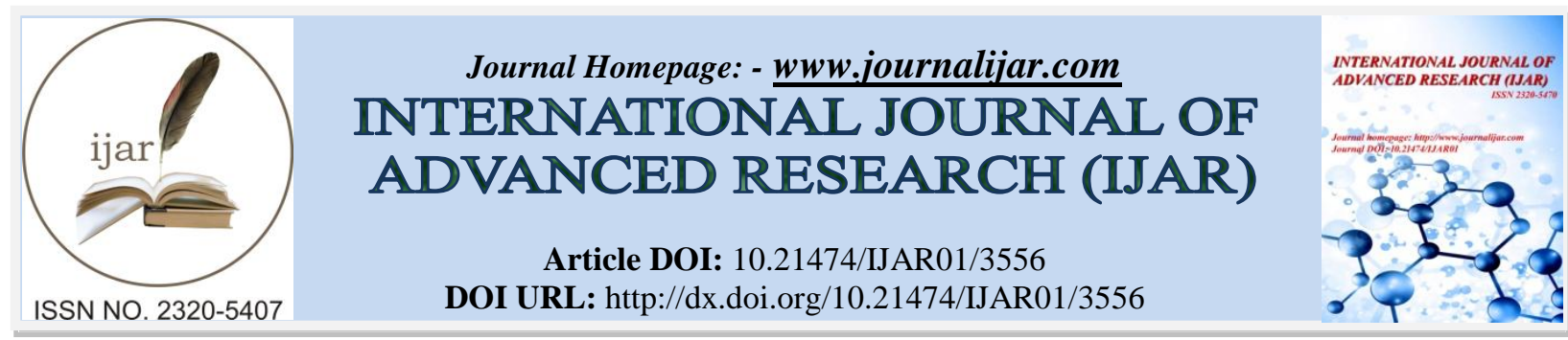

RESEARCH ARTICLE

\title{
PHYTOCHEMICAL SCREENING, ANTIOXIDANT \& ANTIBACTERIAL ACTIVITY OF GREEN SYNTHESIZED SILVER \& GOLD NANOPARTICLES USING LEAF EXTRACT OF ZIZIPHUS NUMMULARIA AND ITS EFFECTIVENESS AGAINST INFECTED DENTINE: AN IN VITRO STUDY.
}

"Kamini Parmar and Dr. O.P. Jangir. Department of Biotechnology, Maharaj Vinayak Global University, Dhand, Tehsil- Amer 302028, Jaipur, Rajasthan.

\section{Manuscript Info}

Manuscript History

Received: 14 January 2017

Final Accepted: 13 March 2017

Published: March 2017

Key words:-

Ziziphus nummularia, Phytochemical Screening, Antioxidant activity. Antibacterial activity, Nanoparticles Synthesis.

\begin{abstract}
Green synthesis is a promising nanotechnological tool for biomedical application. The present investigation demonstrates a rapid biogenic approach for the synthesis of gold and silver nanoparticles using biologically active and medicinal important Ziziphus nummularia leaf extract as a reducing and stabilizing agent under ambient conditions. To our knowledge, this is the first report where Zizyphus nummularia leaf extract was found to be an appropriate plant source for the green synthesis. The presence of various phytochemicals viz. polyphenols, alkaloids and flavonoids, were investigated by following standard biochemical methods. The silver and gold nanoparticles were characterized by UV-visible spectroscopy (Systonic 2203) that showed Surface Plasmon Resonance (SPR) for both gold and silver nanoparticles at 551 and $438 \mathrm{~nm}$. Scanning electron microscopy (SEM) revealed that gold nanoparticles were observed as nanorods in shape with $54 \mathrm{~nm}$ in size while the size of the silver nanoparticles was measured $200 \mathrm{~nm}$ with spherical shape. The antioxidant activity was determined by 2, 2- diphenylpicrylhydrazyl (DPPH) assay. Further, the antibacterial activity of synthesized silver and gold nanoparticles showed effective inhibitory activity against Staphylococcus aureus and Sstreptococcus mutans.
\end{abstract}

Copy Right, IJAR, 2017,. All rights reserved.

\section{Introduction:-}

Nanoscience and nanotechnology has the capability to provide the most dynamic area of research in modern materials science (P.P Singh \& C. Bhakat 2012). Nanoparticles are exceptional materials with exclusive features and electifying applications in diverse fields (R Geethalakshmi and DVL Sarada 2012). Metal nanoparticles, such as those containing silver $(\mathrm{AgNp})$ and gold $(\mathrm{AgNp})$ hold enormous application in different fields like medicine, electronics, energy saving, environment, textile, cosmetics due to their unique optical, electrical, and photothermal properties (C. Ramteke et al. 2013). The most important properties of silver nanoparticles are its antibacterial, antifungal and antimicrobial effects (A. Singh et al. 2010) while gold nanoparticles show optical and catalytic property in chemical reaction (Michael Quinten 2011). They also have strong surface plasmon resonance oscillations (L. Rivas 2001). The synthesis of nanoparticles is very quiet novel process leading to truly green chemistry in plants which supply advancement over chemical and physical method (A. Gole et al. 2001). As it is cost efficient and environment friendly easily scaled up for large scale synthesis and in this method there is no need to high pressure, temperature and toxic chemicals (D. Ashok Kumar. 2012). Conventionally, nanomaterials are

Corresponding Author:- Kamini Parmar.

Address:- Department of Biotechnology, Maharaj Vinayak Global University, Dhand, Tehsil- Amer 664 
synthesized by chemical or physical methods; Green synthesis of nanoparticles is the most promising method of synthesis (A. Leela \& M. Vivekanand. 2008).

Dental caries is a chronic and infectious disease characterized by demineralization of the tooth due to acids formed by bacteria in biofilms produced on its surface. Streptococcus mutans is considered one of the most cariogenic microorganisms present in human dental biofilm (M.R. Linares et al. 2014). The cariogenicity of these bacteria is based on the metabolism of sucrose, which are a substrate for membrane-bound glucosyl transferases and a proficient growth substrate for S. mutans (V. A. Lee et al. 2010) (W. I. Loesche et al. 1986). The earlier approach to the treatment of using hand excavation was a painful and ineffective process of carries removal (A. Juntavee et al. 2014).

Medicinal plants play a key role in the innovation of new therapeutic agents for drug development (Elavazhgan $\mathrm{T}$. Arunachalam KD 2011). Zizyphus nummularia is belongs to the family Rhamnaceae. It is a shrub or thorny small bush or small tree with medicinal properties (M. Goyal et al. 2012). It is commonly known as wild jujube (English) and jharberi (Hindi). Zizyphus nummularia grows in great quantity in the arid and semi-arid areas of India. Especially in Rajasthan it forms $14 \%$ of the whole composition of the grassland flora (A. H. Shah et al. 1990). The local communities used Zizyphus nummularia as analgesic, anti-inflammatory, anti-colds and anti-coughs medicine (M. Goyal et al. 2011) and also contain numerous bioactive phytochemical materials such as polyphenols, flavonoids, pectin, saponins and alkaloids (A. F. Morel et al. 2009) (M. Lalitha Eswari et al. 2013). The leaves of Zizyphus nummularia have been reported to possess strong antioxidant properties (Salma Nasrullah Malik. 2015) and have also been used to treat diabetes and chronic fever in India. Fruits and roots of $Z$. nummularia are used to cure sun stroke and healing cuts. This plant is also used for removing stones (A. H. Shah et al. 1990) (S. Chandra et al. 2011).

To our knowledge, this is the first report where Zizyphus nummularia leaf extract was found to be an appropriate plant source for the green synthesis of silver and gold nanoparticle (D. Ashok Kumar 2012). Bioreduction of chloroauric acid $(\mathrm{HauCl})$ and silver nitrate $(\mathrm{AgNO}(3))$ for the synthesis of silver and gold nanoparticles correspondingly with the plant extract, Zizyphus nummularia (Rhamnaceae) (D. Mubarak Ali et al. 2011). The rapid development of stable silver and gold nanoparticles is observed (S. S. Shankar et al. 2004). However, no studies have examined the antibacterial potential of nanoparticles using leaf extract of Ziziphus nummularia in an infected dentin model. The purpose of this in vitro study was to evaluate the antibacterial activity of Silver and Gold Nanoparticles against S. mutans and to find its efficacy as an intracanal medicament (R. Suvarna et al 2014) (D. R. Herrera 2016)

\section{Methodology:-}

\section{* Materials and Sample Collection:-}

All chemical reagents including chloroauric acid $\left(\mathrm{HAuCl}_{4}\right)$, silver nitrate $\left(\mathrm{AgNO}_{3}\right) 0.135 \mathrm{mM}$ DPPH solution, FolinCiocalteu's phenol reagent, methanol and gallic acid (CDH, Central Drug House, New Delhi) were obtained and used as received. Muller Hinton agar (MHA) from obtained from (Hi-Media Pvt. Ltd. Mumbai). All the chemicals used were of the highest purity available. Ultrapure water was used for every experiment (Milli-Q System; Millipore Corp.).Fresh Z. nummularia leaves collected from the Maharaj Vinayak Global University, (Jaipur, Rajasthan India) were used as a plant source.

\section{* Preparation of Plant Extract:-}

$20 \mathrm{gm}$ of fresh leaves of Z. nummularia were washed thoroughly with doubled- distilled water and were then cut into small piece. These finely cut piece were then mixed with $100 \mathrm{ml}$ double- distilled water and this mixture was kept for boiling about 20 minutes. After cooling, it was filtered through Whatman Filter paper. 1 and further use for biosynthesis of silver and gold nanoparticles.

\section{* Synthesis of Silver Nanoparticles:-}

$10 \mathrm{ml}$ aqueous extract of $Z$. nummularia leaves was added to $90 \mathrm{ml}$ of silver nitrate solution $(1 \mathrm{mM})$. The solution was allowed to react at room temperature and after 30 minutes change in the color was observed (colorless to intense yellow). 


\section{* Synthesis of Gold Nanoparticles:-}

$5 \mathrm{ml}$ aqueous extract of $Z$. nummularia leaves was added to $5 \mathrm{ml}$ of chloroauric acid solution ( $1 \mathrm{mM})$. This solution mixture was exposed to room temperature for 2 hour. Dark brown color was observed then analyzes the peak value of these particles with the help of UV Vis Spectrophotometer.

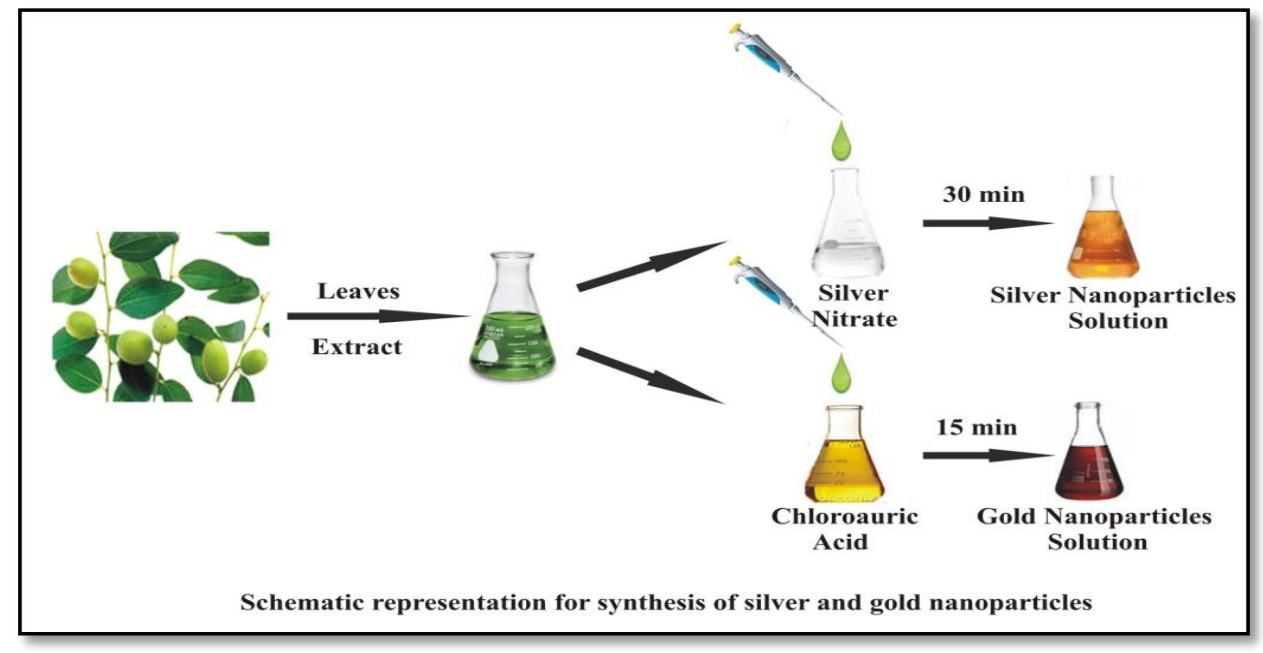

Fig. 1:- Schematic representation for synthesis Ag \& AuNPs

\section{- Characterization of Synthesized Nanoparticles:-}

$\mathrm{Ag}$ and AuNPs obtained from Z. nummularia were characterized by recording UV-Vis absorption spectra using Double Beam UV-visible spectrophotometer 2203 through a quartz cell with $10 \mathrm{~mm}$ optical path that demonstrated peak value. The samples were packed in a quartz cuvett of $1 \mathrm{~cm}$ light- path length and the light absorption spectra were given in reference to deionized water.

The morphology of the colloidal sample was examined using Scanning electron microscopy (SEM-Zeiss) and Transmission electron microscopy (TEM-FEI Tecnai G2 S-Twin) with ultrahigh resolution (UHR) pole piece operating at an accelerating voltage of $300 \mathrm{kV}$ that revealed size and shape.

\section{* Extraction of antioxidant:-}

The leaves of Ziziphus were cleaned and cut into small pieces and then oven dried at $50^{\circ} \mathrm{C}$ for 72 hour. The dried sample was pulverized by a mechanical grinder and passed through $250 \mu \mathrm{m}$ mesh and then stored at $4^{\circ} \mathrm{C}$ until use. In the extraction process about $1 \mathrm{gm}$ of Ziziphus powder were weighed in universal bottles and $10 \mathrm{ml}$ of $50 \%$ methanol was added. Then solution was homogenized using homogenizer at $24^{\prime} 000 \mathrm{rpm}$ for 1 minute after that sample was centrifuged for $10 \mathrm{~min}$. the supernatants were collected for further analysis.

\section{* Radical DPPH Scavenging Activity:-}

Antioxidant activity of the Ziziphus nummularia extract and standard was measured on the basis of the radical scavenging effect of the stable DPPH free radical. The 2, 2 diphenyl- 1- picrylhydrzyl was dissolving in methanol to prepare the DPPH solution. The DPPH solution was dilute 42 times with methanol to obtain 0.9 absorbance at 516 $\mathrm{nm}$ with the help of spectrophotometer. $1 \mathrm{ml}$ of DPPH solution was added into $100 \mu \mathrm{l}$ of Ziziphus leaf extract solution. This mixture was shaken in vortex and kept in dark room for 2 hour. After that mixture was transferred to micro plate and absorption was measured in spectrophotometer. The following equation (3.1) calculates the percentage of DPPH scavenging activity: the percentage of DPPH scavenging activity was calculated using the following equation: Radical scavenging $(\%)=\left[\left(\mathrm{A}_{0}-\mathrm{A}_{1} / \mathrm{A}_{0}\right) \times 100\right]$ where $\mathrm{A}_{0}$ is the absorbance of the control and $\mathrm{A}_{1}$ is the absorbance of the sample extracts (Salma Nasrullah Malik 2015) (S. Gupta et al. 2016).

\section{* Phytochemical Screening:-}

Total Flavonoid Content:

Plant extract $(0.5 \mathrm{ml}$ of $1: 10 \mathrm{mg} / \mathrm{ml})$ in methanol were separately mixed with $0.1 \mathrm{ml}$ of $10 \%$ aluminium chloride, $1.5 \mathrm{ml}$ of ethanol, $0.1 \mathrm{ml}$ of $1 \mathrm{M}$ sodium acetate and $2.8 \mathrm{ml}$ of distilled water. Solution was kept for 30 min at room 
temperature and absorbance of the reaction mixture was measured by double beam UV spectrophotometer at 415 nm.

\section{Total Phenolic Content:}

The total phenolic content of Ziziphus nummularia extract was determined by using Folin- Ciocalteu method. Standard Gallic acid (10gm) was dissolve in $100 \mathrm{ml}$ of distilled water in volumetric flask $(100 \mu \mathrm{g} / \mathrm{ml} \mathrm{of}$ stock solution). $1.5 \mathrm{ml}$ of Folin- Ciocalteu reagent and $10 \mathrm{ml}$ of distilled water, diluted according to the label specification to each of the volumetric flasks. After $5 \mathrm{~min} 4 \mathrm{ml}$ of $1 \mathrm{M}$ sodium carbonate was added and made up to $25 \mathrm{ml}$ with distilled water. Simultaneously leaf extract $(0.5 \mathrm{ml}$ of $1: 10 \mathrm{mg} / \mathrm{ml})$ in methanol were separately mixed with above reagent. After 30 minutes absorbance at $765 \mathrm{~nm}$ was observed.

\section{Total Alkaloid Content:}

$5 \mathrm{gm}$ sample of $Z$. nummularia was weighed into $250 \mathrm{ml}$ and $200 \mathrm{ml}$ of $10 \%$ acetic acid in methanol was added and kept for 48 hours. After filteration the extract were concentrated on a waterbath. Concentrated ammonium hydroxide was added drop by drop into the extract until the precipitation was complete. After that solution was washed with dilute ammonium hydroxide and filtered. The filtrate obtained was dried and weighed.

\section{* In Vitro Study On Infected Dentine:-}

Firstly infected tooth (Incisor, Premolar \& Molar) collected from Maharaj Vinayak Global University in the department of Conservative and Endodontics. Healthy and infected tooth dipped into nanoparticles solution synthesized from Ziziphus nummularia. $\mathrm{pH}$ of solution should be maintained at 5.5. Nanoparticle solution kept in B.O.D. incubator $\left(37^{\circ} \mathrm{C}\right)$ for overnight incubation. After overnight incubation results was observed.

\section{Results:-}

Silver and gold nanoparticles were synthesized using leaf extract of Ziziphus nummularia. Due to the reaction of the metal salt, color of the solutions changed colorless to yellow and dark brown, indicating the formation of silver and gold nanoparticles, respectively.

\section{* UV Visible Spectroscopy:-}

Reduction of silver ions into silver nanoparticles using leaf extracts $Z$. nummularia was proved by the change of color from colorless to intense yellow. The UV- Visible spectra show an absorption band at $438 \mathrm{~nm}$ indicating the presence of silver nanoparticles.

For gold nanoparticles, bioreduction of $\mathrm{Au}$ ions was observed by visualizing the color change from colorless to dark brown. UV- Visible spectra confirmed the presence of gold nanoparticles with absorption band at $551 \mathrm{~nm}$.

\section{* SEM Results:-}

The scanning electron microscopy (SEM-Zeiss) has been engaged to characterization the size, shape and morphologies of formed silver and gold nanoparticles. From the images (Fig. 2) it is evident that the morphology of AgNP is nearly spherical and AuNP is indicating niddle shaped rod. The average particle size examined with the help of SEM images is observed to be $200 \mathrm{~nm}$ of silver nanoparticles while $54 \mathrm{~nm}$ of gold nanoparticle. 


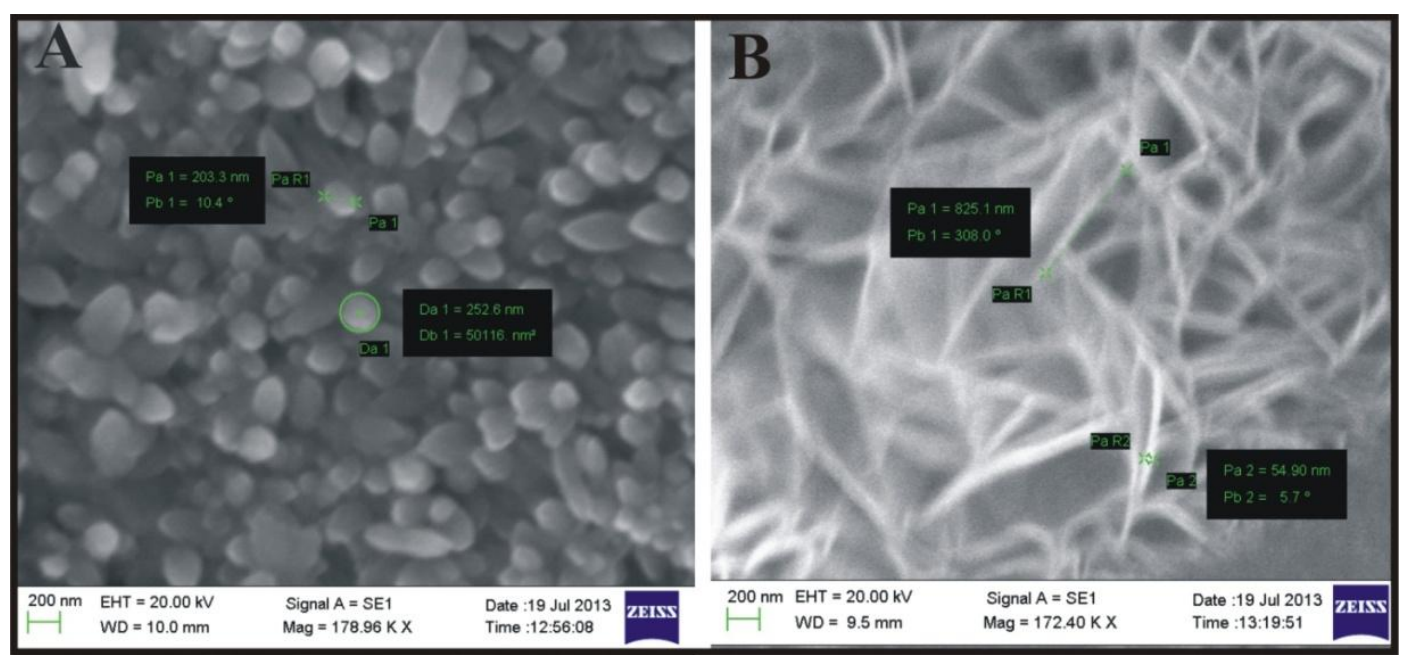

Fig. 2:- SEM Images of (A) Silver nanoparticles and (B) Gold Nanoparticles

\section{* TEM Results:-}

HR- TEM micrograph was examined the morphology of silver and gold nanoparticles. The data obtained from TEM images found distinct shape and size of polydisperse nanoparticles. These images suggest that the gold particles are niddle shaped rod and silver nanoparticles are mostly spherical in shape. It is evident that the size distribution of gold NPs between $50-60 \mathrm{~nm}$ and $200 \mathrm{~nm}$ for the silver NPs. The spherical and niddle shaped rod of the particle, as visible in Figure 3, is due to the fact that when a particle is produced, in its initial state, it tries to obtain a shape that corresponds to minimum potential energy.

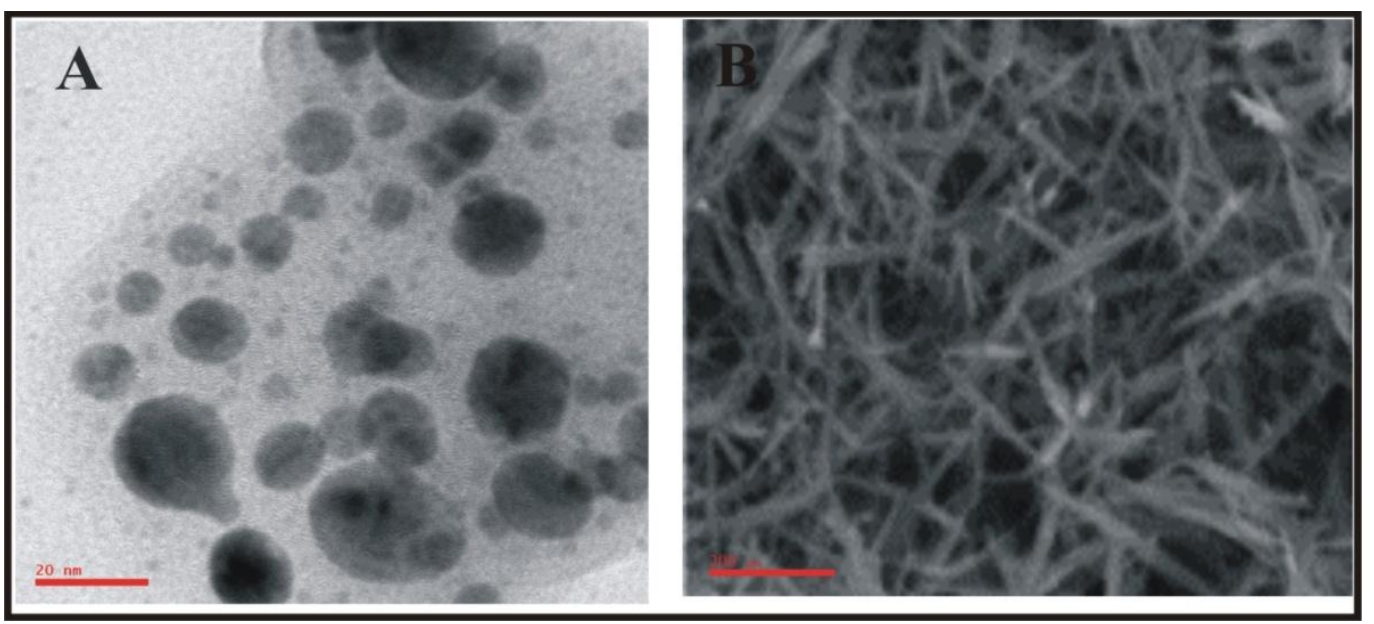

Fig. 3:- TEM Images of (A) Silver nanoparticles and (B) Gold Nanoparticles

\section{* Antibacterial activity:-}

The agar diffusion method was used to notice the effect of the concentrations of both silver and gold against Streptococcus mutans (MTCC 1890) \& Staphylococcus aureus (MTCC 7443) bacteria. The in vitro antibacterial activity of the samples was evaluated by using Mueller-Hinton Agar (MHA). The results as shown that Streptococcus mutans \& Staphylococcus aureus were susceptible to the gold and silver nanoparticle both (Fig. 4). The zones of inhibition created by the gold \& silver particles of the Ziziphus nummularia compared favorably with control in this study. The activities of gold and silver nanoparticles against $S$. mutans \& S. aureus suggested that these particles could be used to treat dental carries 


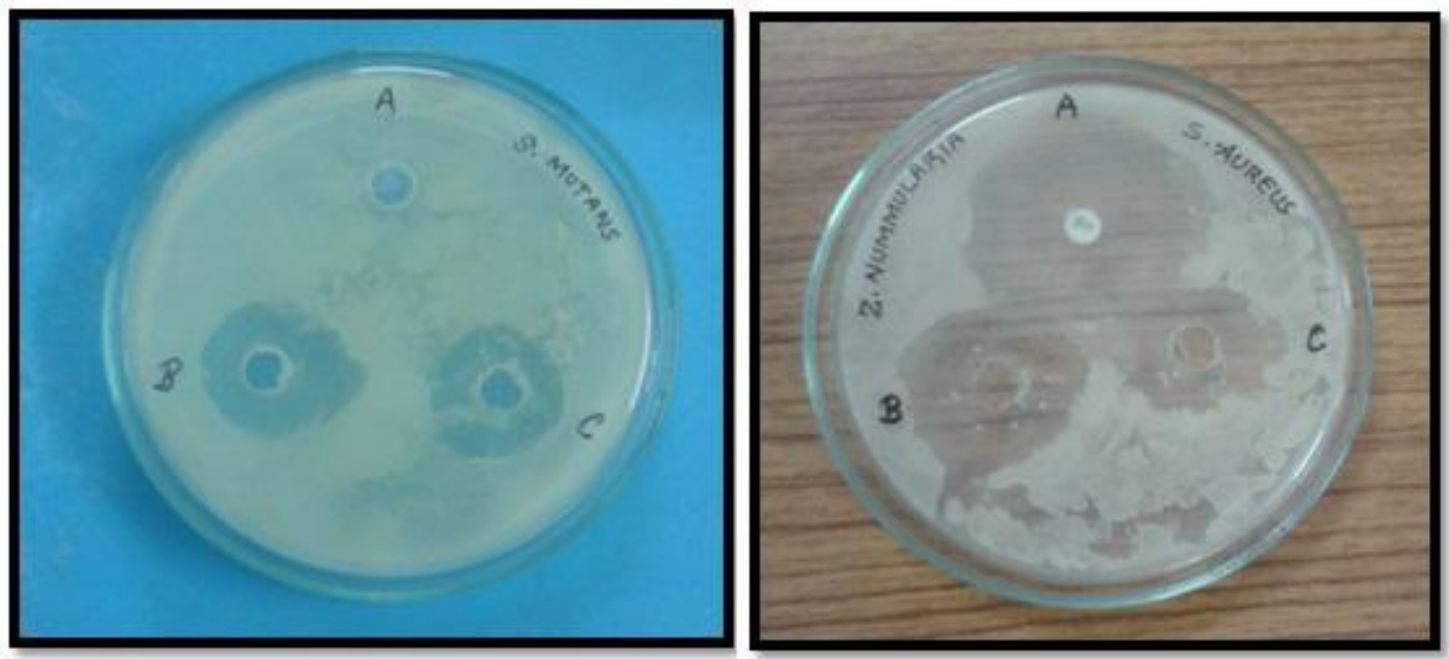

Fig. 4:- Antibacterial Activity against Streptococcus mutans \& Staphylococcus aureus (a) Control (b) Silver NPs (c) Gold NPs

\section{* DPPH Assay (Radical Scavenging Activity):-}

A huge number of methods have been developed to estimate antioxidant capacity of medicinal herbs extracts. But only some of them used widely due to the complexity of measuring total antioxidant capacity owing to limitations associated with methodological issues. DPPH radical scavenging activity assay is performed to monitor the ability of compound to act as free radical scavengers and to analyze the antioxidant activity of plant extract. The methanol extracts of Ziziphus leaves sample was calculated for their IC50 values against DPPH.IC50 is the required concentration of Ziziphus nummularia antioxidants to scavenge 50\% DPPH radicals in the reaction mixtures. Free redical scavenging property was calculated. The antioxidant activity of Ziziphus leaves is illustrated in Table Figure (1 and 5). These data indicated that the Ziziphus nummularia extract is kinetically active scavenger against DPPH under the testing conditions.

Table 1: - DPPH Free radical scavenging activity of Ziziphus Nummularia

\begin{tabular}{|l|l|l|l|}
\hline Sample & Concentration $(\mathrm{mg} / \mathrm{mL})$ & \% Inhibition & IC50 \\
\hline \multirow{5}{*}{ Ziziphus nummularia } & $\mathbf{0 . 0 2 3}$ & $\mathbf{3 1 . 9 1}$ & \multirow{3}{*}{0.03832} \\
\cline { 2 - 3 } & $\mathbf{0 . 0 4 6}$ & $\mathbf{6 0 . 4 8}$ & \\
\cline { 2 - 3 } & $\mathbf{0 . 0 6 9}$ & $\mathbf{8 4 . 4 1}$ & \\
\hline \multicolumn{2}{|l}{ Control Absorbance $\mathbf{0 . 0 0 1 8 4}$} &
\end{tabular}




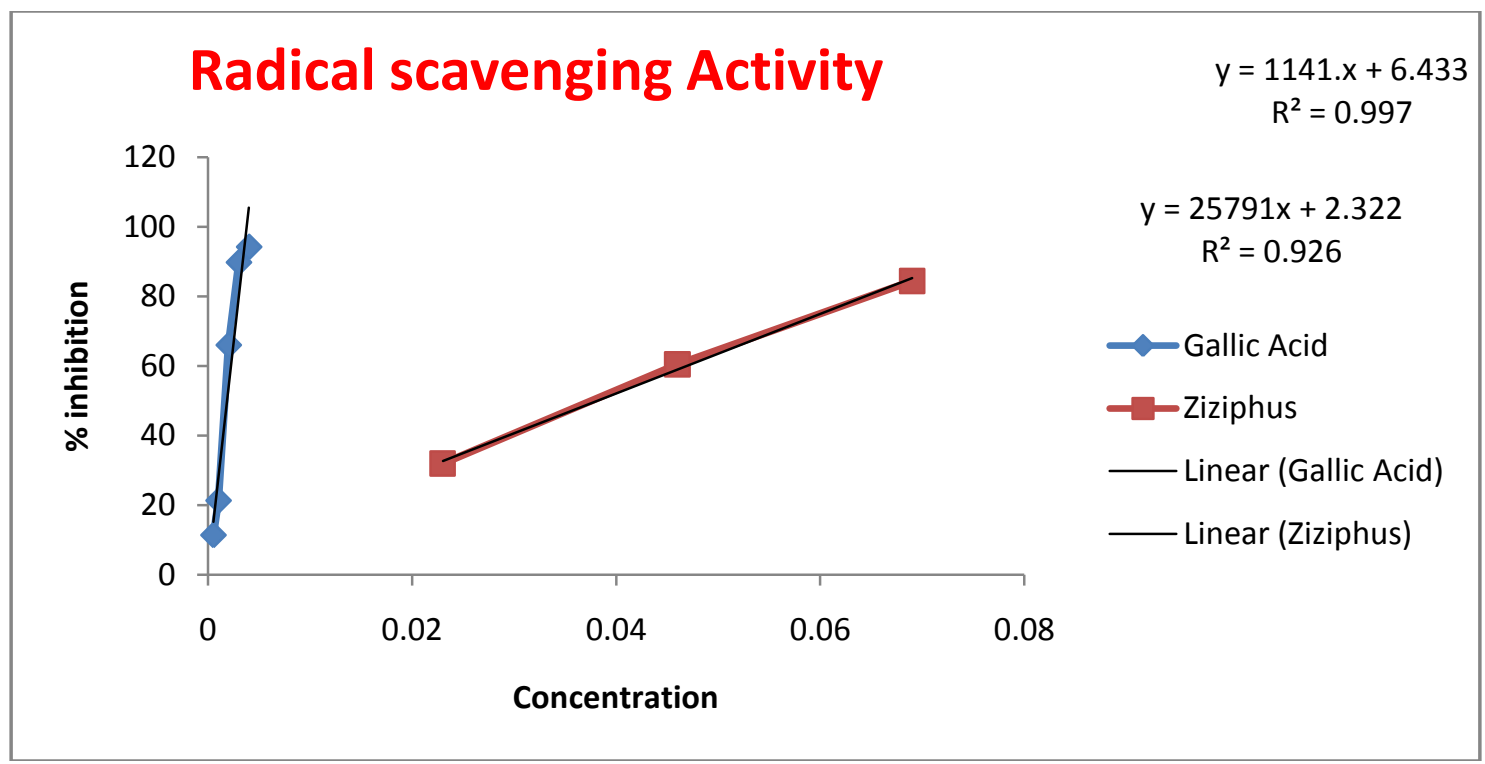

Fig. 5:- Graphical representation of DPPH scavenging activity of Ziziphus nummularia

\section{* Phytochemical Screening:-}

Phytochemicals component in the plants are identified to be biologically active complexes and accountable for various activities such as antibacterial, antimicrobial, anti inflammatory and antioxidant. In the present study, the phytochemical screening of Ziziphus nummularia leaf extract had been performed with methanol extract and the results shown in Table 2 respectively. It revealed the presence of alkaloid, flavonoid and phenolic compound present in the extracts.

The total phenolic content was found to be $1.37 \%$ while total flavonoid content was found to be $0.066 \%$ in methanol extract. Total alkaloid content was found to be $4.04 \%$ in plant powder.

Table 2: - Phytochemicals detected in Ziziphus nummularia Extract

\begin{tabular}{|l|l|l|}
\hline Parameters & Results & Method \\
\hline $\begin{array}{l}\text { Extractive Value } \\
\text { (Methanol Solvent) }\end{array}$ & $12.01 \%$ & API Method 2008 \\
\hline $\begin{array}{l}\text { Total Flavonoid Content } \\
\text { (By UV spectroscopy) }\end{array}$ & $0.066 \%$ & API Method 2008 \\
\hline $\begin{array}{l}\text { Total Phenolic Content } \\
\text { (By UV spectroscopy) }\end{array}$ & $1.37 \%$ & API Method 2008 \\
\hline Total Alkaloid Content & $4.04 \%$ & API Method 2008 \\
\hline
\end{tabular}

API: Ayurvedic Pharmacopeia of India

\section{* In Vitro Study on infected Dentine}

Silver \& gold nanoparticle extracted from Z. nummularia provides antibacterial activity against acid producing bacteria, Streptococcus mutans. Healthy and infected tooth dipped into nanoparticles solution (pH 5.5). Nanoparticle solution kept in B.O.D. incubator $\left(37^{\circ} \mathrm{C}\right)$ for overnight incubation. Dentine starts dissolve after overnight incubation in AuNPs \& AgNPs solution ( $\mathrm{pH} 7$ ) was observed. The use of these NPs in the treatment of dental caries was found to be very effective.

It is proved that this project is successful in reducing infected dentine further studies must be conducted to test the carcinogenic properties either in animal model or in cell lines in order to evaluate the application of AgNPs \& AuNPs as a bactericidal agent. 


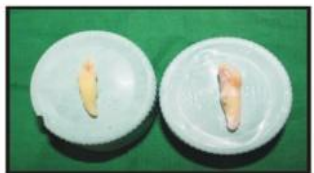

Incisor

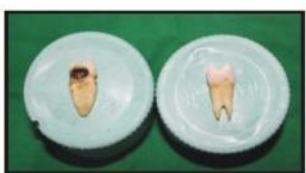

Premolar

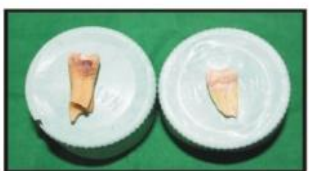

Molar
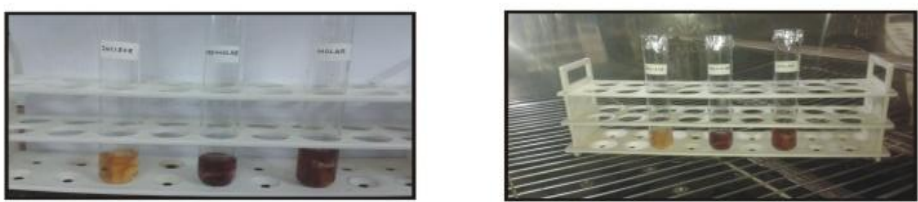

Healthy \& Infected tooth dipped in NPs solution (pH 5.5) and kept in B.O.D. Incubator for overnight Incubation
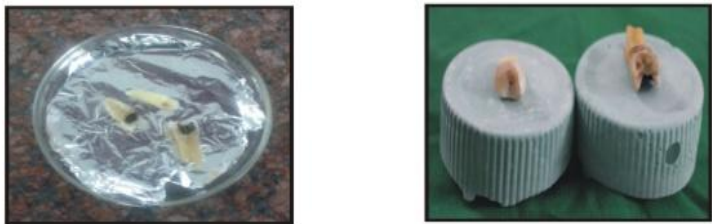

Dentine Starts Dissolve in Ag \& AuNPs Solution (pH 7)

Fig. 6:- Schematic representation of Ag \& AuNPs Effect on Infected Dentine

\section{Conclusion:-}

The current method eludes the use of toxic chemicals for the synthesis of gold and silver nanoparticles so it can be used for biological applications. This research has successfully employed for the development of silver \& gold nanoparticles with spherical \& nanorod shapes by using Ziziphus nummularia as reducing and stabilizing agent. This synthesis approach of gold and silver nanoparticles is rapid, cost effective and can be widely used in biological systems \& medical system. Nanoparticles have been extensively researched because of their unique physical properties, chemical reactivity and potential applications in biological labeling, biosensing, drug delivery, antibacterial, antimicrobial and antiviral activity, detection of genetic disorders, gene therapy, and DNA sequencing. According to the results, Ziziphus leaves contain alkaloid, flavonoid and phenolic compounds, it can be considered as an excellence source of antioxidant compounds.

Silver \& gold nanoparticle extracted from Z. nummularia provides antibacterial activity against acid producing bacteria, Streptococcus mutans \& Staphylococcus aureus. The use of these NPs in the treatment of dental caries was found to be very effective. This project is successful in reducing infected dentine further studies must be conducted to test the carcinogenic properties either in animal model or in cell lines in order to evaluate the application of AgNPs \& AuNPs as a bactericidal agent.

\section{References:-}

1. Ashok kumar D. (2012) Rapid and Green Synthesis of silver nanoparticles using the leaf extracts of Parthenium Histerophorus: A Novel Biological Approach. International Research Journal of pharmacy. 3: 2.

2. Chandra. S. R. Dave and M. Kaneria. (2011) In Vitro antioxidant Property of Some Indian Medicinal Plants. Res J. Med. Plant. 5: 169-179.

3. Elavazhgan T. Arunachalam KD. (2011)Memecylon edule leaf extract mediated green synthesis of silver and gold nanoparticles. 2011(6): 1265-1278.

4. Geethalakshmi R and DVL Sarada, Int J Nanomedicine. (2012) Gold and silver nanoparticles from Trianthema decandra: synthesis, characterization, and antimicrobial properties. Int J. Nanomedicine. 7: 5375-5384.

5. Gole A. Dash C. Ramakrishnan VS. Sainkar S. Mandale A. Rao M. Sastry M. (2001) Pepsin-Gold Colloid Conjugates: Preparation, characterization and enzymatic activity. Langmuir. 17:1664-1679.

6. Goyal M, D. Sasmal and B.P. Nagori. (2012) Analgesic and Anti-inflammatory Activity of Ethanolic Extract of Zizyphus nummularia. Research journal of medicinal plant. 6: 521-528.

7. Goyal. M. D. Sasmal and B.P. nagori. (2011) Review on Medicinal Plants Used By Local Community Of Jodhpur District Of Thar Desert. Int. J. Pharmacol. 7:333-339. 
8. Gupta S. Mukesh Sharma. O.P. Jangir. (2016) Assessment Of Phytochemicals, A-Tocopherol, B-Carotenoid And Antioxidant Potential Of Wheat Bran (Triticumaestivum). International journal of advanced research. 4(8): 1130-1136.

9. Herrera D R. Jorge Enrique Durand-Ramirez. Amanda Falcao. Emmanuel João Leal Nogueira Da Silva. Elizabete Brasil Dos Santos. Brenda Paula Figueiredo De Almeida GOMES. (2016) Antimicrobial Activity And Substantivity Of Uncaria Tomentosa In Infected Root Canal Dentin. Braz. Oral Res. 30: 1.

10. Juntavee A. Jomjai Peerapattana. Ariya Ratanathongkam. Nartsajee Nualkaew. Supaporn Chatchiwiwattana. Panta Treesuawan. (2014) The Antibacterial Effect on Apacaris Gel on Streptococcus mutans: An in vitro study. Int J. Clin Pediatr Dent. 7(2): 77-81.

11. Lalitha eswari M. R. Vijaya Bharathi. N Jayshree. (2013) Preliminary Phytochemical Screening and heavy Metal Analysis of leaf Extract of Ziziphus oenoplia (L) Mill. Gard. International Journal of Pharmaceutical Science and Drug Research. 5(1): 38-40.

12. Lee V.A., R. Karthikeyan, H.R. Rawls and B.T.(2010) Amaechi, Anti-cariogenic effect of a cetylpyridinium chloride-containing nanoemulsion, Journal of Dentistry, 38(9): 742-749.

13. Leela A. and M. Vivekanand, (2008) Tapping the unexploited plant resource for the synthesis of silver nanoparticles, 7(17): 3162-3165.

14. Loesche, W.I. (1986) Role of Streptococcus mutans in human dental decay, Microbiological Reviews, 50(4): 353-380.

15. Malik S. N. (2015) Evaluation of Antibacterial and Antioxidant activity of Ginger and Ziziphus Leaves. International journal of Pharmtech. 7(4): 554-559.

16. Morel A. F. G. Maldaner and V.Ilha. (2009) Alkaloid: chemistry and Biology. Elsevier UK, 79-141.

17. MubarakAli D, Thajuddin N, Jeganathan K, Gunasekaran M. (2011) Plant Extract Mediated Synthesis of Silver And Gold Nanoparticles And Its Antibacterial Activity Against Clinically Isolated Pathogens. Colloids and surfaces B Biointerfaces . 87(2): 159-163.

18. Quinten M, (2011) Optical Properties of nanoparticles System, WILEY-VCH.

19. Ramteke C, Tapan Chakrabarti, Bijaya Ketan Sarangi, and Ram-Avatar Pandey.(2013) Synthesis of Silver Nanoparticles from the Aqueous Extract of Leaves of Ocimum sanctum for Enhanced Antibacterial Activity. Journal of Chemistry. 2013 (2013): 7.

20. Rivas L, Sanchez-Cortes S, Garcia-Ramos JV, Morcillo G. (2001) Growth of silver colloidal particles obtained by citrate reduction to increase the Raman enhancement factor. Langmuir. 17: 574-577.

21. Ruis Linares M. Carmen Maria Ferrer-Luque. Teresa Areas- Moliz. Paula de Castro. Beatriz Aguodo and Pilar Baca. (2014) Antimicrobial Activity Of Alexidine, Chlorhexidine And Cetrimide Against Streptococcus Mutans Biofilm. Annals of Clinical Microbiology and Antimicrobials. 13:41

22. Shah.A. H. M. Tariq and M. A. Al-Yahyam. (1990) Studies on the alkaloidal fraction from the stem bark of Ziziphus nummularia. Fitoterpia, 61: 452-469.

23. Shiv Shankar S. Akhilesh Rai. Absar Ahmad. Murali Sastry. (2004) Rapid synthesis of Au, Ag, and bimetallic $\mathrm{Au}$ core-Ag shell nanoparticles using Neem (Azadirachta indica) leaf broth. Journal of colloid and interface science. 275(2): 496-502.

24. Singh A, D Jain, M.K Upadhya, N. K Nandelwal, (2010) Green Synthesis Of Silver Nanoparticles Using Argemone Mexicana Leaf Extract And Evaluation Of Their Antimicrobial Activities. Digest Journal Of Nanomaterials And Biostructures, 5: 483-489.

25. Singh P.P., Chittaranjan Bhakat, (2012) Green synthesis of gold and silver nanoparticles from leaves and bark of Ficus Carica for Nanotechnological Applications. International Journal of Scientific and Research Publications, 2(5): 2250-3153,

26. Suvarna R, Sham S Bhat and K. Sundeep Hegde. (2014) Antibacterial Activity of Turmeric against Enterococcus faecalis An In vitro Study. International Journal of Current Microbiology and Applied Sciences. 3(2): 498-504. 